Research matters not covered by the reports of the specialist advisory bodies are relegated to a final section of the report and include the research of the African Studies Branch of the Colonial Office into problems of African administration and the noticeable expansion in the work of the Colonial Liaison Section of the Building Research Station, which nevertheless still finds it difficult to meet its present commitments. The work of the Section has included climatological studies, such as solar radiation in West Africa, the mechanism of heat transfer in building structures under tropical conditions, and the design of buildings for air-conditioning in the tropies, and a study of the fundamental causes of weathering of building materials in different climates is projected. Reference is also made to the Falkland Islands Dependencies Survey, a major task of which is topographical mapping of the Dependencies, and to the Geodetic and Topographical Surveys, where recruitment of field staff kept level with transfers and resignations. Good progress was made with geodetic surveys, and the triangulation and photocontrol work over twenty-thousand square miles between Dar es Salaam and Jinja, in Tanganyika, and down into the Kilombero Valley, was completed as far as weather permitted.

The overseas scientific staff of the Colonial Geological Surveys was further increased from 196 to 202 , but the number of vacancies has risen to more than thirty in consequence of the desire of some territories to enlarge their geological surveys. In some territories the fundamental task of mapping has been impeded by the diversion of geologists to other duties-for example, in connexion with the Volta River project and Tema harbour. Progress in establishing eight seismographs in the Windward and Leeward Islands and Trinidad is reported. Meteorological research was again somewhat restricted by the shortage of qualified meteorologists; but establishment of a separate research section of the East African Meteorological Department was being considered and the Departmont has continued to study the artificial control of rainfall and has used cetyl alcohol successfully to reduce evaporation from reservoirs. No laboratory work was carried out on Colonial road-research problems, but the Committee on Colonial Road Research has now been appointed. A report issued by the Colonial Road Research Liaison Officer on his visit to the Caribbean area in 1954 indicates that the basic problems for research there are much the same as in other Colonial territories, with an outstanding need to develop a method of pavement design suitable for traffic and sub-soil conditions in the various territories.

\section{MECHANISM OF PHASE TRANSFORMATIONS IN METALS}

A SYMPOSIUM on the "Mechanism of Phase A Transformations in Metals" was organized by the Metal Physics Committee of the Institute of Metals and held in London at the Royal Institution on November 9. Nucleation and growth changes were considered during the morning session, when the discussion was based on an invited review paper by Drs. H. K. Hardy and T. J. Heal and on seven contributed papers. The afternoon meeting was devoted to martensitic changes, and there were nine contributed papers, in addition to a review paper by
Drs. B. A. Bilby and J. W. Christian. Each session was introduced by a rapporteur (Dr. Hardy and Dr. R. W. Cahn), and there were fourteen speakers in the morning discussion and seventeon in the afternoon. In the circumstances, a comprehensive report is not possible in these columns, and this survey will merely mention some of the views that seemed important to me.

A pleasing feature of the symposium was the large number of speakers from abroad. Opening the morning discussion, Prof. A. Guinier (Conservatoire des Arts et Métiers, Paris) gave a masterly survey of recent work on the early stages of precipitation. He showed a series of remarkable electron micrographs (or radiographs), obtained by $\mathrm{R}$. Castaing, using a new fine electron-beam technique with very thin solid copper-aluminium specimens. The $\theta^{\prime}$ and $\theta^{\prime \prime}$ (or Guinier-Preston [2]) precipitates were clearly visible, the latter being thin platelets of length about $1 \mu$ and thickness less than $100 \mathrm{~A}$. At very high magnifications, a regular variation in the back. ground is believed to show individual GuinierPreston [1] zones. Prof. Guinier also directed attention to the distinction between Guinier-Preston zones in copper-aluminium alloys, which consist of enriched copper platelets in a uniform matrix, and those in aluminium-silver alloys, where the spherical silver-enriched regions are surrounded by silverdepleted regions of matrix. Similar 'complexes', though of different shape, are believed to occur in copper-nickel-iron and nickel-chromium-aluminium alloys, and to be responsible for 'side-band' phenomena in powder photographs.

Among the subsequent speakers concerned with pre-precipitation effects, Dr. A. Seeger (Max-Planck Institut, Stuttgart) suggested a dislocation model for the energetics of formation of Guinier-Preston [2] zones. Dr. J. Nutting (University of Cambridge) maintained the view already expressed in his paper with Mr. G. Thomas that white spots observed in electron micrographs correspond to the formation of Guinier-Preston [1] zones, and Dr. W. H. Taylor (University of Cambridge) said that M. E. Hargreaves's explanation of side-bands was essentially equivalent to that proposed by Prof. Guinier. Prof. C. S. Smith (Institute for the Study of Metals, Chicago) suggested the application of topological principles to segregates forming during the early stages of precipitation; it might be that growth of segregates occurs because an equilibrium array cannot be attained. Miss J. M. Silcock (Fulmer Research Institute) described some recent structural work, and Dr. A. Berghézan (Centre de Recherches d'Antony, France) emphasized the importance of imperfections produced by quenching or by external stresses.

Prof. G. Borelius (Kungl. Tekniska Hogskolan, Stockholm) showed that there are, after all, probably no large discrepancies between measured lattice diffusion-rates and the rates of early precipitation phenomena. He discussed the first stage of precipitation, which he called primary clustering, and which may be shown by electrical resistance measurements before detectable diffraction effects are produced. The paper given by Prof. Borelius, with Mr. L. E. Larrson, and some of his remarks, were concerned with lead-tin alloys, and Dr. O. Krisement (MaxPlanck Institut, Düsseldorf) reported further work on this system. In contrast to D. Turnbull's results, he found that a single kinetic law did not apply at all temperatures, which suggests that the spinodal curve may have some influence. Krisement's 
description of the precipitation process, however, seemed to be closely similar to Turnbull's model of cellular precipitation.

Further remarks on precipitation from solid solution were made by Mrs. M. K. McQuillan (Metals Division, Imperial Chemical Industries, Ltd.), who described some anomalous effects in titaniumchromium alloys, and by Mr. F. B. Pickering (United Steel Companies) and Dr. G. Pomey (Irsio, France), both of whom discussed sigma phases in relation to the paper by Dr. H. J. Goldschmidt (B.S.A. Group Research Centre). Dr. Pomey showed that in some alloys nucleation is heterogeneous, and cold-working produces many more nuclei. Another topic at the symposium was the allotropic change in pure tin, which formed the subject of a paper by Dr. E. O. Hall (University of Sheffield). Dr. Groen (Technische Hogeschool, Delft) emphasized the different behaviour of pure tin and of tin-mercury alloys, and Prof. Smith suggested two simple experiments which might yield pure grey tin in compact form. The other papers of the morning session were concerned with precipitate morphology (Dr. H. I. Aaronson, Carnegie Institute of Technology), superlattice formation (Dr. H. Steeple and Prof. H. Lipson, Manchester College of Technology), and structural work on titaniumvanadium alloys (Miss Silcock, Mr. M. H. Davies and Dr. Hardy).

The afternoon discussion was opened by Prof. F. C. Frank (University of Bristol). He thought the erystallographic problems are now largely solved, but criticized the dilatation parameter used by J. S. Bowles and J. K. Mackenzie, since, if this represents an elastic strain, it implies an effective Poisson's ratio of -1 . Prof. Frank drew an analogy with the cleavage of mica to emphasize that the experimental results should not be expected to agree exactly with predictions based on some simple theoretical postulate (for example, an invariant plane as the habit plane). A point of physical significance, still to be explained, is why in iron-carbon alloys there is an abrupt change in the habit plane as the carbon content is varied.

Prof. Crussard (Institut de Recherches de la Sidérurgie, Saint-Germain-en-Laye) presented views on martensite essentially different from those in the review paper. He described experiments to show that stabilization in retained austenite is due to the diffusion of carbon or nitrogen atoms, and suggested that nucleation is always partly dependent on thermal activation, although it is necessary in solids to consider the energy of elastic waves rather than to apply reaction-rate theory in the usual manner. In support of this, he cited recent experiments in the U.S.S.R. on isothermal transformation at liquid helium temperatures. Prof. Crussard believed that a dynamic approach is necessary in considering the growth process, which he likened to the propagation of a shock wave. Calculations based on this model are being made in collaboration with Dr. Krisement, and he believed that the compatibility equations will ultimately lead to the crystallographic criteria used in the phenomenological theories.

The conventional theories of martensite crystallography were discussed by Dr. D. S. Lieberman (University of Illinois), who described a simple graphical method for finding the habit plane in any transformation from the invariant plane strain condition, and by Dr. Bilby (University of Sheffield), who described the latest results obtained by the prism-matching and surface-dislocation approaches.
Both he and Lieberman have found that a lattice invariant shear on a $\{111\}$ austenite plane gives approximately both the Kurdjumov-Sachs orientations and habit plane and the low-carbon $\{111\}$ habit plane without the need for dilatation or other length changes within the habit plane. Mr. R. Bullough, working at Sheffield, has obtained a general parametric solution for the habit plane for any set of lattice principal strains and specified shear elements. Other speakers on crystallography were Dr. T. Ll. Richards (Metals Division, Imperial Chemical Industries, Ltd.) and Dr. K. W. Andrews (United Steel Companies).

Transformations in low-carbon steels were dealt with by Dr. A. R. Entwisle (University of Sheffield), who presented convincing evidence that the habit plene is $\{111\}$, and by Dr. A. P. Miodownik (Battersea Polytechnic, London), who pointed out the rather anomalous position in which, since the formation of ferrite in pure iron sometimes produces relief effects, it is a martensitic transformation on Bilby and Christian's definition. Dr. Seeger discussed the transformation in cobalt with special reference to a contributed paper by Drs. F. Sebilleau and $H$. Bibring (Office National d'Etudes et de Recherches Aeronautiques) and reiterated his belief in the correctness of the dislocation-node model for this change. Dr. Christian (University of Oxford) referred to recent evidence obtained at Oxford by $\mathrm{Mr}$. P. Gaunt that a macroscopic shape deformation occurs in both cobalt and the analogous $\gamma \rightarrow \varepsilon$ trans. formation in iron-manganese alloys.

The remaining papers contributed to the afternoon meeting dealt with the transformations in $\beta$-brass (Drs. D. Hull and R. D. Garwood, of University College, Cardiff) and in uranium-chromium (Mr. B. R. Butcher and Mr. A. H. Rowe, of the Atomic Energy Research Establishment, Harwell), the correspondence in the uranium transformation (Dr. W. M. Lomer, of Harwell), nucleation problems (Dr. M. A. Jaswon, of the Imperial College of Science and Technology, London), crystal geometry (Dr. Ll. Richards and Dr. W. T. Roberts), bainite reactions (Dr. Krisement and Prof. F. Wever) and the stabiliza. tion of austenite (Dr. S. G. Glover and Mr. T. B. Smith, of the University of Birmingham). Bainite was discussed by Dr. L. Habraken and Dr. Miodownik, the selection of the correspondence by Dr. Cahn (University of Birmingham), Dr. Lieberman, and Dr. Christian, stabilization by Mr. Kumar (University of Sheffield), and the thorny problem of isothermal versus athermal nucleation by several speakers. The meeting closed half an hour late with many people still wishing to contribute.

A minor point which emerged from both discussions was the dissatisfaction folt by several speakers with the present nomenclature. Prof. Smith pointed out that neither nucleation nor growth is the prerogative of nucleation and growth changes alone, and it was also felt that the present extension of the term martensite to cover the wide class of transformations which show a shape change in the transforming region is not wholly suitable. The difficulty about such a situation, of course, is that the existing usage is established; the problem has arisen largely because the kinetic features on which Greninger and Troiano based their classification of transformations have gradually had to be replaced by other criteria.

In conclusion, it is necessary to applaud the care and thoroughness with which the two rapporteurs 
managed to summarize so much material, and the success of the chairmen (Profs. G. V. Raynor and A. G. Quarrell) in keeping speakers to their allocated times. The papers and discussion will be published in the Monograph and Report Series of the Institute of Metals.

J. W. Christian

\section{BIOLOGISTS AND NATIONAL SERVICE}

$\mathrm{T}$

HE Institute of Biology has made inquiries of the Miristry of Labour and National Service about the opportunities open to graduate biologists in the Services ( $J$. Inst. Biol., 3, No. 1 ; Novem. ber 1955). The position appears to be as follows. All science and engineering graduates entering the Forces aro considered for National Service commissions, and in the past about 40 per cent of them have been commissioned during their National Service. Both in the Royal Navy and the Royal Air Force, science graduates are accepted for National Service only if they can be recommended by a pre-call-up officers' selection board for a National Service commission. In the Army all graduates are called up in the ranks; but each is given an opportunity of being considered for a National Service commission during the period of his basic training.

There are comparatively few opportunities for a graduate in the biological sciences to be employed in any of the three Services in a capacity which will make direct use of his qualifications. So far as the Navy is concerned, his acceptance is unlikely. The demands of the Navy are mainly for mechanical and electrical engineers, mathematicians and physicists, and it does not usually have any requirement for graduates in the biological sciences. In the Royal Air Force, a comparatively small number of graduates in biology is accepted for National Service commissions in the Education Branch. It is also open to any National Service recruit to opt for service in the General Duties Branch for training as a pilot.

The War Office has recommended that a graduate in the biological sciences should apply for service in either the Royal Corps of Signals, the Royal Artillery, the Royal Engineers or the Royal Armoured Corps, where his scientific background is likely to be particularly valuable. There is, of course, nothing to prevent a science graduate from applying for service in any branch, technical or non-technical, and acceptance for a commission will depend solely on qualities of leadership and character and does not depend on technical or academic qualifications, except in so far as a potential officer must be intelligent and able to express himself clearly. Commissions in the Royal Army Education Corps are not given to National Service men; but a graduate in biology, especially if he holds the postgraduate Certificate of Education, may elect to do his service in that Corps where he could expect to be appointed sergeant instructor. The Royal Army Medical Corps is normally officered by medically qualified men; but an occasional vacancy occurs for a physiologist, biochemist or entomologist in commissioned rank. Otherwise, biology graduates may be appointed as laboratory technicians or in similar posts, and promotion to sergeant rank is possible.

An increasing number of science graduates now apply for short-service commissions as an alternative to National Service. These are voluntary regular engagements and usually involve a minimum of three years full-time service. Short-service commissions are available for science (including biology) graduates in the Education Branch of the Royal Air Force or in the Royal Army Educational Corps, as well as in other branches of the Royal Air Force and the Army.

There is no 'allocation' of scientists to defence work; but there is a number of projects of high priority carried on by government departments and private firms on which science graduates may be employed and given deferment on the applications of the government department concerned. Most of the vacancies are for physicists, mathematicians, chemists and engineers: biologists are required only on rare occasions. Deferment can also be granted for certain appointments in the Celonial Agricultural Service, for which biologists are much more in demand.

\section{INTERNATIONAL SURVEY OF PROGRAMMES OF SOCIAL DEVELOPMENT}

YN accordance with a resolution of the United Nations Economic and Social Council, the Bureau of Social Affairs of the United Nations Secretariat, in co-operation with the International Labour Office, the United Nations Educational, Scientific and Cul. tural Organization, the Food and Agriculture Organization and the World Health Organization, has prepared a survey of national and international measures taken to improve social conditions throughout the world*. Entitled "International Survey of Programmes of Social Development", it is concerned primarily with measures taken since 1945 , and with those taken by governments rather than by voluntary or private organizations, and is intended to supplement the "Preliminary Report on the World Social Situation". The survey brings out the remarkable recent expansion of such programmes throughout the world, an expansion which has necessitated the report being limited to the outlining of trends and developments, using concrete cases only for illustrative purposes. The report should be particularly useful to all concerned with Colonial development and welfare and with technical assistance generally, whether under the Colombo Plan or in other ways.

An introductory chapter reviewing the similarities and differences in national approaches to social welfare, production and rural development points out that, in practically all the types of programme surveyed, the three problems constantly being encountered are those of obtaining adequate personnel to execute the programmes, adequate information to guide them, and adequate resources to finance them. Shortages of trained personnel are experienced by countries at all levels of development. Training abroad on fellowships has made an important but limited contribution to the supply of the higher-level technical and professional workers in some countries; attempts have been made in many countries to deal with the maldistribution among the professions, and * International Survey of Programmes of Social Development.
Pp. iv + 200 (New York: United Nations; London: H.M.S.0., 1955.) 2 dollars, 15s., 8 Sw. fr. 